\title{
AS EMOÇÕES NAS INTERAÇÕES E A APRENDIZAGEM SIGNIFICATIVA
}

\author{
Flávia Maria Teixeira dos Santos ${ }^{1}$
}

\section{Resumo}

A teoria da aprendizagem significativa considera a educação como o conjunto de experiências cognitivas, afetivas e psicomotoras que contribuem para o desenvolvimento do estudante. As inter-relações entre significação e afetividade podem ser aprofundadas a partir de uma base teórica da psicologia neurocognitiva. Neste texto propomos alguns elementos teóricos para o aprofundamento e a consideração explícita da vertente emocional do conhecimento e da aprendizagem significativa, articulando a teoria educacional de Novak à abordagem neurobiológica de António Damásio.

Palavras-chave: aprendizagem significativa, emoções e sentimentos.

\begin{abstract}
The meaningful learning theory considers the education as the set of cognitive, affective and psychomotor experiences that contribute for the learner's development. The relationships between meaningful and affectivity can be deepened from a theoretical base of neurocognitive psychology. In this text we consider some theoretical elements for the deepening and the explicit consideration of the emotional source of the knowledge and the meaningful learning articulating the Novak's educational theory and the neurobiology theory of António Damásio.
\end{abstract}

Key-words: meaningful learning, emotion and feeling.

\footnotetext{
${ }^{1}$ Faculdade de Educação - Universidade Federal do Rio Grande do Sul - flavia.santos@ufrgs.br
} 


\section{Aprendizagem Significativa}

“A aprendizagem significativa subjaz à integração construtiva entre pensamento, sentimento e ação que conduz ao engrandecimento humano" (Moreira, 2000, p. 43). Assim, qualquer evento educativo é, segundo Novak, uma ação para intercambiar significados e sentimentos entre o estudante e o professor.

Joseph Novak propõe uma teoria de educação ampla da qual a teoria da aprendizagem significativa faz parte (Idem, p.39). Considera a educação como o conjunto de experiências cognitivas, afetivas e psicomotoras que contribuem para o desenvolvimento do indivíduo, seres humanos que pensam, sentem e atuam (fazem). Assim, a produção de conhecimento é um processo de intercâmbio e negociação de significados; é uma construção humana que coloca em jogo pensamentos, ações e sentimentos e, nesse sentido, é uma construção que se produz em dadas condições e em um determinado contexto.

Uma das condições para a aprendizagem significativa, segundo Ausubel e Novak, é que o estudante apresente uma predisposição para aprender, ou seja, o evento educativo é acompanhado de uma experiência afetiva. "A hipótese de Novak é que a experiência afetiva é positiva e intelectualmente construtiva quando o aprendiz tem ganhos em compreensão; reciprocamente, a sensação afetiva é negativa e gera sentimentos de inadequação quando o aprendiz não sente que está aprendendo" (Moreira, 2000, p.42). Novak aponta para o papel da afetividade na regulação das relações de significação entre o professor e os estudantes e na estreita inter-relação entre predisposição para aprender e aprendizagem significativa.

Neste trabalho discutimos essa estreita interdependência entre afetividade e significação sob a ótica dos aspectos emocionais que orientam as interações no cotidiano das aulas. Utilizaremos como referenciais argumentos vinculados à pesquisa neuropsicológica, a despeito da tradição da pesquisa em interação em sala de aula estar focada sobre aspectos micro e macro-sociológicos (van Zanten, 1995). O estabelecimento de uma base "biológica" para nossas análises consiste em uma tentativa de procurar no indivíduo e em suas emoções a manifestação dos aspectos sócio-culturais e, portanto, contextuais, definidores da aprendizagem significativa dos estudantes nas situações interativas.

Nosso principal objetivo é aprofundar a discussão relativa a esta 
interdependência entre emoção e aprendizagem, procurando contribuir para a efetiva consideração da vertente afetiva na análise do processo de elaboração conceitual e aprendizagem significativa do sujeito.

\section{As Emoções Regulam as Interações Sociais}

As emoções e os sentimentos são aspectos das interações aos quais não tem sido dada suficiente ênfase na pesquisa em Ensino de Ciências ${ }^{2}$, apesar de tacitamente todos reconhecerem a importância das emoções na interação social.

Segundo António Damásio as emoções têm função social e papel decisivo no processo da interação. As emoções são adaptações singulares que integram o mecanismo com o qual os organismos regulam sua sobrevivência orgânica e social. Em um nível básico, as emoções são partes da regulação homeostática ${ }^{3}$ e constituemse como um poderoso mecanismo de aprendizagem. Ao longo do desenvolvimento, “as emoções acabam por ajudar a ligar a regulação homeostática e os 'valores' de sobrevivência a muitos eventos e objetos de nossa experiência autobiográfica" (Damásio, 2000, p. 80). As emoções fornecem aos indivíduos comportamentos voltados para a sobrevivência e são inseparáveis de nossas idéias e sentimentos relacionados a recompensa ou punição, prazer ou dor, aproximação ou afastamento, vantagem ou desvantagem pessoal etc.

No entanto, definir o que são as emoções não é uma tarefa simples. As dificuldades nascem da diversidade dos tipos de manifestações emocionais e da diversidade de teorias divergentes nos vários domínios da pesquisa psicológica que, a partir de estudos experimentais, enfocam o tema das emoções. Griffithis (1997) considera que um conceito geral de emoção não tem nenhum papel no futuro da psicologia, pois seriam necessários pelo menos dois conceitos mais específicos. Além disso, uma conceituação específica não necessariamente implica que o conceito cotidiano de emoção possa desaparecer do nosso pensamento. Essa conclusão é

\footnotetext{
${ }^{2}$ Alguns trabalhos têm procurado tratar o tema a partir de diferentes referenciais teóricos, por exemplo: Simpson et al., 1994; Printrich et al., 1993; Lee e Andersen, 1993, Palmero e Palmero, 1998. Além disso, periódicos importantes da área têm dedicado números especiais à discussão do tema: International Journal of Science Education, 25(9), 2003; Cambridge Journal of Education, 26(3), 1996.

${ }^{3}$ A homeostasia, segundo Damásio (2000, p. 60-61), "associa-se às reações fisiológicas coordenadas e em grande medida automáticas que são necessárias para manter estáveis os estados internos de um organismo vivo", tais como temperatura, concentração de oxigênio ou pH em nosso corpo.
} 
elaborada após uma meticulosa e interessante análise sobre os vários programas de pesquisa que têm investigado o fenômeno emocional.

Griffithis discute as abordagens que sustentam que as emoções são tipos de eventos psicológicos e analisa abordagens antigas que tratam as emoções como experiências introspectivas, caracterizadas pela qualidade e intensidade da sensação, em que o inerente prazer ou desprazer provocado por essas qualidades leva a pessoa a agir de maneira característica. Discute também abordagens que dependem do contraste entre pensamento e emoção. Entretanto, suas análises se sustentam principalmente na abordagem naturalista, denominada "affect program", que é baseada na teoria evolucionária e na etologia humana, e tornou-se a abordagem dominante na Psicologia. Os experimentos sobre a expressão facial, elaborados a partir do trabalho de Darwin sobre emoção, principalmente os realizados por Paul Ekman, são fundamentais para o "affect program". A idéia central da teoria é que as reações emocionais são complexas, coordenadas e automáticas. Elas normalmente envolvem mudanças corporais internas e externas no indivíduo (Idem, p. 77).

Griffithis descreve ainda a abordagem da construção social da emoção, avalia diferentes concepções de "construção social" e discute a visão de que há várias respostas emocionais, e sua ocorrência depende da existência de modelos culturais. Essas respostas são interpretadas pelos sujeitos de uma sociedade como naturais e voluntárias, quando na verdade elas são produzidas em conformidade com as normas culturais locais. Em alguns casos, a produção de uma resposta emocional pode envolver um planejamento subconsciente em conformidade com esse modelo. Em outros casos, o modelo cultural pode reforçar certos comportamentos reconhecidos como adequados.

A diversidade de teorias que sustentam os diferentes conceitos de emoção utilizados na Psicologia resulta em caloroso debate filosófico, metodológico e de categorias psicológicas. Evitaremos essa polêmica, que foge aos objetivos deste trabalho, lançando mão de uma conceituação tradicional que descreveremos a seguir.

No século XIX, Darwin (1872/1965) propôs um poderoso modelo de explicação "histórico-adaptativa" para a emoção ao estabelecer uma descrição anatômica da expressão facial humana. Suas investigações produziram a descrição dos detalhes da expressão facial e muscular que acompanham várias emoções. Ele sugeriu homologias para reações em diferentes espécies e possíveis funções da expressão, 
hoje e no passado evolucionário. Assim, a expressão da emoção seria um vestígio das reações em espécies ancestrais.

Ekman e Friesen (1971, 1978), ao realizarem uma série de replicações dos experimentos de Darwin sobre as expressões faciais, chegaram a um padrão morfológico de cada emoção. Os estudos de Ekman incluem experimentos com diferentes culturas e com outros elementos da reação emocional e seus trabalhos, assim como os de Darwin tratam de emoções básicas como medo, surpresa, raiva, nojo, tristeza/pesar e felicidade/alegria.

Segundo Griffithis (1997, p. 77), para Ekman e seus seguidores as reações emocionais são complexas porque envolvem muitos elementos. Elas normalmente incluem mudanças faciais expressivas, reações músculo-esqueléticas, mudanças vocais, mudanças no sistema endócrino e, conseqüentemente, mudanças no nível hormonal e no sistema nervoso autônomo.

As emoções são coordenadas: vários elementos ocorrem conjuntamente em padrões ou sequiências reconhecíveis. Elas são tratadas como síndromes, isto é, elas têm muitos elementos, e um elemento isolado não constitui a essência da emoção. As emoções freqüentemente envolvem estados qualitativos de consciência, mas esses estados não são mais centrais para a identificação das emoções do que as características das expressões faciais. A teoria da evolução das emoções é concebida como um modelo de respostas envolvendo a atividade de vários sistemas corporais e cognitivos. As emoções consistem em reações automáticas. O fluxo da informação perceptual para os mecanismos controladores das reações emocionais está separado do fluxo de informação e percepção para os processos cognitivos superiores, responsáveis pela ação intencional. Segundo Griffithis (1997, p. 97), há um sistema modular que é o gatilho da emoção e que é influenciado pelo mecanismo de aprendizagem. O sistema de gatilho não está completamente isolado dos processos cognitivos superiores. Esses processos cognitivos podem afetar a manifestação das emoções de várias maneiras. O trabalho de Ekman e Frietzen (1971, p.128), sobre as regras utilizadas culturalmente, sugere que os processos cognitivos podem bloquear e ativar reações emocionais automáticas.

Apesar das várias críticas dirigidas ao "affect program" novos experimentos têm sido realizados. Os trabalhos mais recentes sobre a expressão facial realizam testes de julgamento em culturas alfabetizadas e entre culturas alfabetizadas e 
analfabetas; analisa os componentes de expressões faciais espontâneas e expressões faciais de crianças cegas de nascença ${ }^{4}$ (Griffithis, 1997, p. 50).

\section{Modelo de Níveis Emocionais}

Damásio (1996, 2000) discute três níveis de emoção: primário, secundário e de fundo. As emoções primárias, que denominaremos emoções básicas ${ }^{5}$, são aquelas tratadas pelos trabalhos de Darwin e de seus seguidores, a saber: alegria, tristeza, medo, raiva, surpresa e repugnância. As emoções secundárias ou sociais incluem embaraço, ciúme, culpa, orgulho etc. E, finalmente, há o que Damásio (2000, p. 74) denomina "emoções de fundo como bem-estar ou mal-estar, calma ou tensão. O rótulo de 'emoção' também foi aplicado a impulsos e motivações e a estados de dor e prazer". Essa classificação nos parece apropriada para a análise do processo de significação e aprendizagem significativa. A ocorrência dessas emoções básicas constitui, ao longo do tempo, os sentimentos que permeiam as interações em aula.

As emoções são adaptações que integram os mecanismos pelos quais os organismos regulam a vida, quer numa reação específica a uma situação quer na regulação do estado interno do indivíduo. Emoções são conjuntos complexos de reações químicas e neurais, formando um padrão; todas as emoções têm algum tipo de papel regulador a desempenhar, levando, de um modo ou de outro, à criação de circunstâncias vantajosas para o organismo em que o fenômeno se manifesta; as emoções estão ligadas à vida de um organismo, ao seu corpo, para ser exato, e seu papel é auxiliar o organismo a conservar a vida (Damásio, 2000, p. 74-75).

O aprendizado e a cultura alteram a expressão das emoções e lhes conferem

\footnotetext{
${ }^{4}$ Testes de julgamento e análise dos componentes são dois dos métodos utilizados por Darwin em suas investigações sobre a expressão facial humana. A análise do componente é uma descrição do papel de vários músculos na expressão facial das emoções. $\mathrm{O}$ teste de julgamento consiste em apresentar às pessoas fotografias, filmes ou desenhos do que parece ser uma clara expressão emocional de outro indivíduo. As pessoas são questionadas sobre qual o estado emocional que elas consideram estar expresso na imagem.

${ }^{5}$ Essa classificação dos diferentes tipos de emoções foi criticada por Griffiths. As críticas dirigem-se principalmente à rigidez e dicotomia da classificação proposta por Damásio (1996). Vejamos: "Damásio acredita que as emoções primárias são inatas enquanto as emoções secundárias são adquiridas. Ele parece referir-se a essa dicotomia para usar os lados de entrada e saída de uma emoção. Sobre o lado de entrada, as emoções primárias são acionadas por estímulos aos quais o organismo é intrinsecamente sensível desde o início da infância. As emoções secundárias são acionadas por estímulos aos quais o organismo tornou-se sensível por meio da experiência. Sobre o lado de saída, as emoções primárias tem consequiências psicológicas estereotipadas. Nas emoções secundárias estes efeitos são modulados de maneira que eles refletem o desenvolvimento individual" (Griffithis, 1997, p. 103). Em trabalho mais recente, Damásio (2000) relativiza a rigidez dessa classificação e é nessa perspectiva que estaremos utilizando esses conceitos.
} 
novos significados. Assim temos, por um lado, os processos biológicos determinantes das emoções e, por outro, os aspectos sócio-culturais. Existem reações emocionais universais que são o resultado da evolução biológica, mas em pessoas adultas elas são subsumidas às reações mais complexas que refletem a cultura e o desenvolvimento individual. Nessa abordagem heterogênea (Griffithis, 1997, p. 132-136) temos a conjugação dos aspectos individuais e dos aspectos sócio-culturais das emoções.

\section{Sentimento, emoção e afeto}

A pesquisa sobre as expressões faciais e o processo emocional teve grande impacto sobre a investigação da atividade do sistema nervoso autônomo. As pesquisas empíricas nesse campo foram muito influenciadas pela teoria da emoção de Willian James (1884/1997, 1893/1987). Antes de James, o processo emocional era descrito da seguinte maneira: a percepção de um evento evoca a emoção, em seguida ocorre a experiência de emoção (sentimento) e finalmente nós observamos expressões físicas e orgânicas da emoção (palpitação, tornar-se pálido, calafrio e a garganta seca) (Vygotsky, 1987). A teoria de James rejeita essa seqüência de "percepção-sentimentoexpressão" e discute que a percepção imediata de um evento ocasiona a manifestação de mudanças orgânicas. De acordo com essa teoria, a consciência de uma emoção é a percepção das mudanças no sistema nervoso autônomo, os quais ocorrem simultaneamente à percepção de algum estímulo externo. A percepção das mudanças constitui a própria consciência da emoção. Sua teoria fundamentalmente estabelece a existência de um mecanismo básico, inflexível e congênito, que ao ser excitado por determinados estímulos produz um padrão específico de reação corporal.

James foi bastante criticado por ter atribuído pouca ou nenhuma importância ao processo de avaliação mental da situação que provoca a emoção. Foi também criticado por não ter estabelecido, em sua teoria, um mecanismo para criar o sentimento correspondente a uma emoção, além de não tecer comentário quanto às possíveis funções da emoção no processo da cognição ou no comportamento. Entretanto, estabeleceu uma base para pesquisas sobre o fundamento neural da emoção.

É apoiado nessa teoria que António Damásio (1996) elabora sua pesquisa sobre a base neural das emoções. Para Damásio, o sentimento emocional é a percepção, no neocórtex, das respostas corporais aos estímulos imediatos, através dos centros 
cerebrais inferiores. No entanto, o autor promove uma ampla análise sobre os aspectos que permaneceram obscuros no trabalho de James.

Segundo Damásio, a análise das emoções e sentimentos reflete dois conjuntos distintos de fenômenos. O termo "sentimento" é utilizado para a experiência mental de uma emoção, enquanto o termo "emoção" é usado para o conjunto de reações aos estímulos externos, muitas delas publicamente observáveis. Para tratar a base neural desses eventos, o autor distingue três etapas de processamento que fazem parte de um contínuo: "Um estado de emoção, que pode ser desencadeado e executado inconscientemente; um estado de sentimento, que pode ser representado inconscientemente, e um estado de sentimento tornado consciente, isto é, que é conhecido pelo organismo que está tendo emoção e sentimento" (Damásio, 2000, p. $57)$.

A distinção dessas etapas tem, segundo o autor, a finalidade de possibilitar a investigação minuciosa do mecanismo emocional. Da mesma maneira, a distinção entre sentimento (experiência mental da emoção) e emoção (conjunto de reações orgânicas) objetiva estabelecer os fundamentos biológicos que ligam sentimento e consciência. Na prática, essa distinção significa que não podemos observar um sentimento em outra pessoa, apesar de podermos observar alguns aspectos das emoções que originam esses sentimentos. Na etapa atual de nossa evolução e na vida adulta, as emoções ocorrem em um contexto de consciência. Podemos observar um sentimento em nós mesmos, sentirmos nossas emoções e sabermos que a sentimos. "A trama de nossa mente e de nosso comportamento é tecida ao redor de ciclos sucessivos de emoções seguidas por sentimentos, que se tornam conhecidos e geram novas emoções, numa polifonia contínua que sublinha e pontua pensamentos específicos em nossa mente e ações do nosso comportamento" (Damásio, 2000, p. 64)

Essa distinção entre emoção e sentimento emocional é importante. Outro termo que devemos precisar é afeto, que é usado freqüentemente como sinônimo de humor ou emoção. Neste texto, entretanto, utilizaremos a palavra afeto de uma maneira genérica, podendo designar emoções, humores, sentimentos. Segundo Damásio (Idem, p. 431), "afeto é aquilo que você manifesta (exprime) ou experimenta (sente) em relação a um objeto ou situação, em qualquer dia de sua vida". 


\section{Processos cognitivos e emoção}

Durante muito tempo a emoção foi analisada como oposta à razão, sendo a razão uma das capacidades mais refinadas da espécie humana e completamente independente da emoção. Recentemente, a neurociência tem procurado investigar como a emoção integra os processos de raciocínio e de tomada de decisão. O trabalho de Damásio (1996), que é realizado a partir de estudos com indivíduos com lesões neurológicas, indica que uma redução seletiva da emoção é tão prejudicial para a racionalidade quanto a emoção excessiva. E, a despeito de avaliações dicotômicas, não é verdade que a razão é otimizada na ausência da emoção. Ao contrário, segundo o autor, é "provável que a emoção auxilie o raciocínio", em especial quando se trata de questões pessoais e sociais que envolvem risco e conflito.

As emoções e sentimentos constituem aspectos centrais na regulação biológica e estabelecem uma ponte entre os processos racionais e os não racionais. Diversos casos clínicos narrados em Sacks $(1995,1997)$ revelam como toda a base afetiva da vida pode ser podada por uma lesão neurológica. Sacks (1995, p. 292) fala sobre um juiz que sofreu uma lesão no lobo frontal do cérebro, em consequiência de fragmentos de uma granada, que pediu sua aposentadoria alegando não mais poder entender com compaixão os motivos de outra pessoa. Poder-se-ia pensar que a falta de emoção e as propensões que as acompanham tornariam um indivíduo imparcial, no entanto o juiz não mais se sentia qualificado para o trabalho, já que "a Justiça envolve sentimento e não apenas o pensamento lógico".

Por outro lado, as emoções desempenham uma função na comunicação de significados a nossos interlocutores e podem, também, ter papel na orientação cognitiva e na compreensão das mensagens e de seu conteúdo. Sacks (1995) narra o caso de Temple Grandin, uma autista com problemas afetivos. Nesse caso não é o afeto em geral que é defeituoso, mas o afeto em relação a experiências humanas complexas, predominantemente as relações sociais, códigos e regras habituais do relacionamento humano e a capacidade de identificar emoções em outras pessoas e compartilhá-las, seu conteúdo e significado. 


\section{Emoção e afetividade}

Possivelmente o único aspecto consensual entre as diferentes abordagens que investigam o fenômeno emocional é o reconhecimento do valor adaptativo das emoções e de sua função na interação social. A interferência dos aspectos emocionais nas aulas e nos processo de significação vem sendo realizada em nossos trabalhos em termos das emoções básicas que são vivenciadas pela professora e pelos estudantes e em relação às emoções de fundo que vão sendo construídas ao longo do tempo, no ambiente das salas de aula (Santos, 1997, Santos e Mortimer, 1998, 2003).

Os eventos emocionais nas interações em aula contribuem para constituir o que Damásio denomina "sentimento de fundo", clima, ou humor nas salas de aula. Efetivamente, esse clima ou humor é determinado pela permanência de certas formas de interação, principalmente pelas emoções básicas e de fundo que passaremos a analisar.

Emoções básicas e o processo interativo: as emoções que foram denominadas básicas envolvem principalmente aquelas que foram tratadas nos trabalhos realizados dentro da tradição da pesquisa emocional apresentada anteriormente. Essas emoções básicas - alegria, tristeza, medo, raiva, surpresa e repugnância - são consideradas universais nos aspectos da expressão facial e da possibilidade de reconhecimento de sua manifestação, como mostraram os trabalhos realizados nos séculos XIX e XX (Damásio, 2000, p. 361).

Certamente, essas emoções básicas não correspondem a toda a gama de comportamentos emocionais verificados nos seres humanos. Além disso, na maior parte do tempo, não experimentamos os sentimentos relacionados a essas emoções básicas. Não permanecemos em um estado prolongado de alegria, tristeza, nojo ou medo, exceto em determinadas patologias psico-sócio-comportametais. Nós experimentamos, normalmente, outros tipos de sentimentos como bem-estar, calma, tensão, irritação etc. Damásio (1996, 2000) os denomina "sentimentos de fundo" e afirma que eles estão associados às emoções de fundo. São esses sentimentos de fundo que ajudam a definir nosso estado mental, muito mais do que as emoções básicas. No entanto, não podemos desconhecer que a existência recorrente de certas emoções básicas num espaço interativo contribui para definir esses sentimentos.

As emoções básicas são geradas por situações extremas. É possível identificar, 
em determinadas condições, a ocorrência de emoções como alegria, tristeza, medo, raiva, surpresa e repugnância, ou emoções derivadas tais como descontentamento, irritação, impaciência etc. Outra característica importante das emoções básicas é o contágio dessas emoções entre os membros de um grupo. No entanto, como apontamos essas emoções básicas, apesar do efeito devastador que podem ter sobre o processo interativo, não permanecem por muito tempo, uma vez que elas dão lugar a sentimentos de fundo que definem o clima ou atmosfera das aulas.

Emoções de Fundo: as emoções de fundo não são tratadas pelas abordagens tradicionais sobre a emoção, que centraram seus estudos sobre os tipos de emoções estudadas por Darwin. Damásio (2000, p. 76) descreve as emoções de fundo em termos de "tensão, irritação, desânimo, entusiasmo, abatimento ou animação sem que nenhuma palavra tenha sido dita para traduzir qualquer um desses possíveis estados". Percebemos as emoções de fundo por meio de detalhes sutis, como a postura do corpo, a velocidade e o contorno dos movimentos, mudanças mínimas na quantidade e na velocidade dos movimentos oculares e no grau de contração da musculatura facial. Os elementos que induzem uma emoção de fundo são geralmente internos. Os próprios processos de regulação da vida podem causar emoções de fundo, mas essas também podem ter como causa processos contínuos de conflito mental, explícitos ou velados, na medida em que esses processos acarretam a satisfação ou a inibição constante de impulsos e motivações. Por exemplo, emoções de fundo podem ser causadas por um esforço físico prolongado, pelo stress ou excesso de trabalho ou por grandes períodos de pressão.

Em suma, certas condições de estado interno engendradas por processos físicos contínuos ou por interações do organismo com o meio, ou ainda por ambas as coisas, causam reações que constituem emoções de fundo. Essas emoções permitem que tenhamos, entre outros, os sentimentos de fundo de tensão ou relaxamento, fadiga ou energia, bem-estar ou mal-estar, ansiedade ou apreensão (Idem, p. 76).

Após longos períodos, estados emocionais tendem a se tornarem razoavelmente freqüentes ou mesmo contínuos. Nesses casos, Damásio sugere que é melhor referir-se a eles como humores em vez de emoções. Uma emoção de fundo, mantida por longo tempo, gera um humor. Damásio (2000, p. 362) destaca alguns dos sentimentos de fundo: "fadiga, energia, excitação, bem-estar, mal-estar, tensão, descontração, arrebatamento, desinteresse, estabilidade, instabilidade, equilíbrio, 
desequilíbrio, harmonia, discórdia". Esses diferentes humores constituem o clima das aulas, que pode ser amigável e acolhedor ou conflituoso e turbulento.

\section{Aspectos emocionais e construção de conhecimento: implicações para a pesquisa}

Por meio dos elementos fornecidos neste texto, evidenciamos o valor adaptativo das emoções e sua função na interação social. Os aspectos afetivoemocionais têm papel determinante no processo de desenvolvimento e constituição (orgânica e social) do indivíduo. Além disso, as emoções desempenham um importante papel no processo de construção de significados em salas de aula, estando relacionadas aos impulsos, interesses e motivações dos estudantes e do professor no trabalho com o conhecimento científico nas aulas.

Como discutimos, é "provável que a emoção auxilie o raciocínio" em especial quando se trata de questões pessoais e sociais que envolvem risco e conflito. As emoções e sentimentos constituem aspectos centrais na regulação biológica e estabelecem uma ponte entre os processos racionais e os não racionais. As emoções desempenham uma função na comunicação de significados a nossos interlocutores e podem ter também papel na orientação cognitiva. A estreita relação entre cognição e emoção refere-se não apenas às emoções básicas que são automáticas e, normalmente, envolvem situações extremas que afetam o indivíduo de uma maneira mais perceptível ao observador externo. Essa relação também se refere aos sentimentos de fundo, aos humores, que contribuem ou funcionam como um obstáculo para a adoção de atitudes e posicionamentos no interior das aulas.

Os estudos realizados (Santos, 1997, Santos e Mortimer, 1998, 2003) levamnos a acreditar que os aspectos que promovem uma relação mais estimulante dos alunos com o conhecimento científico estão relacionados não só à competência discursiva do professor na promoção do processo de significação nas interações em aula ou na contextualização do conhecimento científico. As emoções e sentimentos de fundo que permeiam as interações em aula são determinantes no envolvimento e motivação do estudante. A construção de emoções e sentimentos de fundo parece exigir, do professor, uma constante reavaliação de suas estratégias e reflexão sobre os efeitos de seus comportamentos não-verbais e expressivos sobre diferentes grupos de alunos. 
Nossos estudos sustentam nossa hipótese de que os sentimentos de fundo que permeiam as interações nas aulas são, em parte, determinados pelas características do primeiro encontro e pelo reforço cotidiano (positivo ou negativo) de determinados padrões interativos, ao longo do ano letivo. Não consideramos que as interações sejam construídas em função de uma "simpatia" ou "antipatia" recíproca e imediata, visto que mesmo que em outros espaços interativos as simpatias possam parecer gratuitas, nas aulas de aula esse processo é construído por meio da trama cotidiana das interações.

Os aspectos teóricos apresentados neste texto podem ter consequiências para se pensar o processo de aprendizagem significativa gerando questões de pesquisa ou fornecendo um aporte conceitual para o tratamento de questões já levantadas: " $A$ começar pela questão da predisposição para aprender. Como provocá-la? Muito mais do que motivação, o que está em jogo é a relevância do novo conhecimento para o aluno. Como levá-lo a perceber como relevante o conhecimento que queremos que construa?" (Moreira, 2005, p.17).

\section{Referências}

CAMBRIDGE JOURNAL OF EDUCATION (1996). The Emotions in Teaching. Cambridge, Carfax - International Periodical Publishers, v. 26, n.3. Special Issue. DAMÁSIO, A. (1996) O Erro de Descartes: emoção, razão e o cérebro humano. São Paulo: Companhia das Letras.

DAMÁSIO, A. (2000) O Mistério da Consciência: do corpo e das emoções do conhecimento de si. São Paulo: Companhia das Letras.

DARWIN, C. (1872/1965) The Expression of the Emotions in Man and Animals. Chicago: University of Chicago Press.

EKMAN, P.; FRIESEN, W.V. (1971) Constants across cultures in the face and emotion. Journal of Personality and Social Psychology. v.17, n.2, p.124-129.

EKMAN, P.; FRIESEN, W.V. (1978) Facial action coding system: investigator's guide. Palo Alto: Consulting Psychologist Press.

GRIFFITHIS, P.E. (1997) What Emotions Really Are: the problem of psychological categories. Chicago: University of Chicago Press.

INTERNATIONAL JOURNAL OF SCIENCE EDUCATION (2003) London: Taylor 
\& Francis, v. 25, n. 9, set. Mini Special Issue.

JAMES, W. (1884/1997) What is an emotion? Mind. n.9. p.188-205 apud GRIFFITHIS, P.E. What Emotions Really Are: the problem of psychological categories. Chicago: University of Chicago Press. 285p.

JAMES, W. (1893/1987) The Principles of Psycology. New York: Holt apud VYGOTSKII, L.S. [1896-1934] Emotions and their development in childhood. In: The collected works of L. S. Vygotsky. Translation: Sobranie Sochinenii. v.1. Problems of general psychology. New York: Plenum Press.

LEE, O.; ANDERSEN, C.W. (1993) Task Engagement and Conceptual Change in Middle School Science Classrooms. American Educational Research Journal, 30(3), p. 585-610.

MOREIRA, M.A. (2000) Aprendizaje significativo: teoria y práctica. Madrid: Visor.

MOREIRA, M.A. (2005) Aprendizagem Significativa Crítica. Porto Alegre.

PALMERO, G.R.; PALMERO, M.L.R. (1998) Una Propuesta de Incorporación de la Vertiente Afectiva del Conocimiento y del Contexto en la V Heurística. Investigações em Ensino de Ciências, 3(3).

PINTRICH, P.R., MARX, R.W. e BOYLE, R.A. (1993) Beyond Cold Conceptual Change: the role of motivational beliefs and classroom contextual factors in the process of contextual change. Review of Educational Research, 63 (2), 167-199.

SACKS, O.W. (1995) Um antropólogo em marte: sete histórias paradoxais. São Paulo: Companhia das Letras.

SACKS, O.W. (1997) O homem que confundiu sua mulher com um chapéu e outras histórias clínicas. São Paulo: Companhia das Letras.

SANTOS, F.M.T. (1997) Afeto, Emoção e Motivação: uma nova agenda para a pesquisa em ensino de ciências. In: I ENCONTRO NACIONAL DE PESQUISA EM ENSINO DE CIÊNCIAS. Porto Alegre: Universidade Federal do Rio Grande do Sul/Instituto de Física da UFRGS, p. 249-255.

SANTOS, F.M.T.; MORTIMER, E.F. (1998) Investigando as Interações Afetivas nas Salas de Aula de Química. In: REUNIÃO ANUAL DA SOCIEDADE BRASILEIRA DE QUÍMICA, 21. Poços de Caldas: Sociedade Brasileira de Química.

SANTOS, F.M.T.; MORTIMER, E.F. (2003) How Emotions Shape the Relationship between a Chemistry Teacher and Her High School Students. International 
Journal of Science Education. vol.25, n.9. p. 1095-1110.

SIMPSON, R.D.; KOBALLA, T.R.; OLIVER, J.S.; CRAWLEY, F.E. (1994) Research on the affective dimension of science learning. In: GABELL, D.L. (Ed.). Handbook of research on Science Teaching and Learning. New York: Macmillan Publishing Company.

VAN ZANTEN, A. H. (1995) Sociologia da Educação: dez anos de pesquisa. Petrópolis: Vozes.

VYGOTSKI, L.S. (1987) Emotions and their development in childhood. In: The collected works of L. S. Vygotsky. Translation: Sobranie Sochinenii. v.1. Problems of general psychology. New York: Plenum Press.

DATA RECEBIMENTO: 17/09/2006

DATA APROVAÇÃO: 28/03/2007 